\title{
Business Contributions to Sustainable Development: A Study of Leading US Retailers
}

\author{
Peter Jones* and Daphne Comfort \\ School of Business and Technology, University of Gloucestershire, Cheltenham, UK
}

\begin{abstract}
There is an increasing recognition of the role businesses can play in contributing to the transition to a more sustainable future and a growing number of large companies have developed corporate sustainability strategies and policies designed to manage their environmental, social and economic impacts. That said, primary research into how companies are addressing and contributing to sustainable development faces a number of a number of challenges but it is important that examinations of these contributions are included in environmental studies curricula. To that end, this review illustrates how five of the leading US retailers report on their sustainability strategies and achievements and offers some critical reflections on retailers' contributions to sustainable development. The paper reveals that all five selected retailers publicly reported on their contribution to sustainable development. However, the authors argue that the retailers' commitments to sustainable development are primarily driven by business imperatives and efficiency gains and that they are couched within existing business models centred on continuing growth.
\end{abstract}

\section{Keywords}

Sustainable development, US retailers, Strategy, External assurance, Economic growth, Environmental studies curricula

\section{Introduction}

There is a growing recognition of the role and importance of businesses in contributing to sustainable development. The Sustainable Development Goals (SDGs), for example, which set out the United Nations agenda to 'address the global challenges we face, including those related to poverty, inequality, climate, environmental degradation, prosperity, and peace and justice' [1] illustrate this trend. The United Nations Global Compact [2] argued that meeting these goals 'will take an unprecedented effort by all sectors in society' but emphasised that 'business has to play a very important role in the process'. More specifically, a growing number of large companies have developed corporate sustainability strategies and policies. These strategies and policies focus on a wide range of environmental, social and economic issues, including climate change, water and energy conservation, waste management, the conservation of natural resources, employee health and well-being, diversity and equality of opportunity, responsible sourcing and local economic development. That said, primary research into how companies are addressing sustainable development faces a number of challenges, including negotiating access to companies; the complexity and geographical reach of large companies who might be seen to be taking a corporate lead in contributing to sustainable development; and issues about measurement and metrics. Arguably, more fundamentally, there are tensions between methodologies that view challenges for sustainable development as socially constructed and those that emphasise the material realities of environmental and social problems [3].

Nevertheless, as the business contribution to sustainable development assumes increasing importance, it is vital that such examinations of these contributions are included in environmental studies curricula. The need for such examinations of corporate contributions for pedagogical purposes is essentially the 'problem statement' for this paper, and in addressing this problem this exploratory review paper suggests that corporate annual sustainability reports offer an accessible way of exploring the current business contribution to sustainable development. More specifically, the paper has two objectives firstly, to illustrate how five of the leading retailers in the US, report on their sustainability strategies and achievements, and secondly, to offer some critical reflections on retailers' and more generally on businesses', contributions to sustainable development. As such, the paper's contribution is to shine some light on the contributions to sustainable

*Corresponding author: Professor Peter Jones, School of Business and Technology, University of Gloucestershire, The Park, Cheltenham, UK

Accepted: March 09, 2019

Published online: March 11, 2019

Citation: Jones P, Comfort D (2019) Business Contributions to Sustainable Development: A Study of Leading US Retailers. Adv Environ Stud 3(1):132-140 
development reported by a number of leading US retailers and more generally, to encourage environmental studies scholars and students to explore and reflect on current business contributions to sustainable development. The main body of the paper begins with a short review of the literature on sustainable development and corporate sustainability and with a description of the frame of reference and the method of enquiry, which underpins the study. This is followed by a review of sustainable development commitments and achievements reported by the selected retailers, which prompts some critical reflections on the nature of the reporting process and on the retailers' contributions to sustainable development.

\section{Literature Review: Sustainable Development and Corporate Sustainability}

The concept of sustainable development is not new. Du Pisani [4], for example, demonstrated 'how the idea of sustainability evolved through the centuries as a counter to notions of progress'. Further he concluded 'fears that present and future generations might not be able to maintain their living standards stimulated a mode of thinking that would inform discourses which prepared the way for the emergence and global adoption of sustainable development' [4]. The concept re-appeared in the environmental literature in the 1970's and since then it has attracted increasingly widespread attention. Barr [5], for example, claimed that 'one of the most pressing and complex question of the early twentieth-first century' is 'how to promote the behavioural shifts necessary for creating the sustainable society'.

The most widely used definition of sustainable development is 'development that meets the needs of the present without compromising the ability of future generations to meet their own needs' [6]. However, defining the concept is not straightforward and there are a number of different and contested meanings. More specifically, there are sets of definitions that acknowledge that all human beings live on one planet with finite quantities of natural resources and fragile ecosystems on which all human life ultimately depends. There are also much more all-embracing definitions, that seek to include ambitious social and economic goals and to meet human needs in an equitable manner.

More critically, Hudson [7] argued that definitions range from 'pallid blue green to dark deep green'. The former Hudson [7] suggested, centre on 'technological fixes within current relations of production, essentially trading off economic against environmental objectives, with the market as the prime resource allocation mechanism', while for the latter 'prioritizing the preservation of nature is preeminent' [7]. Hudson [7] also suggested that the dominant view of sustainable development is grounded in a bluegreen discourse of ecological modernization' and 'claims that capital accumulation, profitable production and ecological sustainability are compatible goals'. Further, he contrasts this view with the 'deep green' perspective, which 'would require significant reductions in living standards and radical changes in the dominant social relations of production'. In a similar vein, a distinction is often made, for example, between 'weak' and 'strong' sustainability and Roper [8] suggested that 'weak sustainability prioritizes economic development, while strong sustainability subordinates economies to the natural environment and society, acknowledging ecological limits to growth'.

During the past two decades, as investors, consumers, governments, interest groups and the media have become more acutely aware of the environmental, social and economic impacts of business activities, so growing numbers of companies have begun to develop sustainability agendas as an integral component of their business strategies and corporate sustainability initiatives have assumed increasing importance. KPMG [9], for example, suggested that 'the evidence that sustainability is becoming a core consideration for successful businesses around the world grows stronger every day'. While there is broad agreement that corporate sustainability is concerned with environmental, social and economic issues, there is little consensus in defining the term and, as with sustainable development, a number of meanings can be identified.

There are definitions, which seem to emphasise business continuity. Dyllick and Hockerts [10], for example, defined corporate sustainability as 'meeting the needs of a firm's direct and indirect shareholders....... without compromising its ability to meet the needs of future stakeholders as well'. There are also definitions that look to include environmental and social goals and to formally incorporate these goals into corporate strategy. van Marrewijk and Werre [11], for example, argued that 'corporate sustainability refers to a company's activities - voluntary by definition - demonstrating the inclusion of social and environmental concerns'. In some ways Amini and Bienstock [12] combined both approaches and argued that corporate sustainability 'embraces the idea that an organization, in order to remain fundamentally sustainable in the long term, must consider all of the contexts in which it is embedded: economic, social and environmental'.

The growing interest in, and commitment to, corporate sustainability has seen the emergence of sustainability reporting across a wide range of companies and organisations. In essence, sustainability reporting is a general term used to describe how a company, or an organisation, publicly reports on its environmental, social and economic impacts and performance. A number of factors seem to be important in helping to explain this trend. These include, the need to comply with a growing volume of environmental and social legislation and regulation; concerns about the cost and scarcity of natural resources; greater public and shareholder awareness of the importance of socially conscious financial investments; the growing media coverage of the activities of a wide range of anti-corporate pressure groups; and more general changes in social attitudes and values within modern societies. More specifically a growing number of companies are looking to publicly emphasize and demonstrate their commitment to sustainability in an attempt to help to differentiate themselves from their competitors and to enhance corporate brand reputation.

That said, relatively little work has been published within 
the academic literature on the sustainable development strategies and achievements of specific companies. Stoughton and Ludema [13] explored a comparative case study of three large, but unnamed corporations, 'with exemplary sustainability standings' to model how sustainability emerges at organizational, functional and individual levels, all of which were seen to be 'essential to the long term success of a commitment to sustainability'. Lock and Steele [14] conducted content analysis of over 200 corporate sustainability reports from 11 European countries in an attempt to review their credibility and this analysis suggested that companies needed to focus on the content of their reports to make them more credible. More recently, however, a literature review [15] included no studies of specific companies.

At the same time, Baumgartner and Ebner [16] claimed that although 'many companies investigate sustainability management and publish sustainability reports, the main focus of this endeavour is unclear' and more positively offered a number of suggestions designed to help companies to verify if their sustainability commitments are consistent with the implementation of their sustainability strategies. While studies of individual companies are limited, some work has been published on specific business sectors. Bonilla-Priego, et al. [17] and de Grosbois [18] reviewed sustainability reporting in the ocean cruising industry and Jones, et al. [19] conducted an exploratory case study of Europe's leading food and drink wholesalers' commitments to sustainability. Wagner [20] explored ways to reconcile environmental and economic performance to improve corporate sustainability sustainability in the European paper industry; and Jones, et al. [21] explored the sustainability strategies and achievements reported by the world's leading hotel groups.

More generally, interest in sustainable development has gathered momentum, so a number of attempts have been made to develop theoretical frameworks connecting nature and society and to emphasise that social and economic development cannot be viewed in isolation from the natural environment. A number of authors [22] have employed stakeholder theory to conceptualise sustainability. In simple terms stakeholder theory is developed around the belief that companies should be sensitive to the interests not just of their shareholders but also those of a wider variety of stakeholders, including suppliers, customers and society at large, and that in so doing they will ultimately be more successful. From a different perspective, Amsler [23] argued that 'the contested politics and ambiguities of sustainability discourses' can be embraced to develop a 'critical theory of sustainability'. She further argued that current debates should be located 'within a broader tradition of social criticism' and that 'competing interpretations of sustainability' should be viewed as 'invitations to explore the complex processes through which competing visions of just futures are produced, resisted and realized'. Castro [24] has sought to lay the foundations for a more radical theory of sustainability by questioning the very possibility of sustainable development under capitalism and arguing that economic growth relies upon the continuing and inevitable exploitation of both natural and social capital.

\section{Frame of Reference and Method of Enquiry}

In an attempt to explore business contributions to sustainable development, the US retail sector, which includes seven of the world's ten leading retailers [25], was chosen for study. On the one hand, 'retailers act as gatekeepers between producers and consumers' [26] and as such, retailers might be seen to be in a singularly powerful position to drive sustainable development in three ways, namely through their own actions, through partnerships with suppliers and through their daily interactions with consumers. Durieu [27], for example, argued that large retailers 'can greatly influence changes in production processes and consumption patterns and are well positioned to exert pressure on producers in favour of more sustainable choices'. On the other hand, the US is the world's largest economy and as such it the faces a wide range of challenges in moving to a more sustainable future. More specifically, five of the largest US retailers namely Walmart, Kroger, Walgreen Boots Alliance, Target and The Home Depot, were selected to illustrate the ways in which retailers publicly reported on their contribution to sustainable development. These five retailers were selected partly because they offered a variety of product ranges and retail formats, and partly because they had published extensive annual sustainable development reports which provided a wealth of information on their approach to sustainability.

Walmart, a multinational retail corporation founded in 1962 in Arkansas, is the world's largest retailer. It operates a chain of hypermarkets, discount department stores, grocery stores, and retail warehouses, has a growing online business, and trades in 29 countries from over 11,000 stores. Kroger was founded in Cincinnati in 1893, and operates from hypermarkets, supermarkets and department stores in over 3,000 locations in 35 states within the US. Walgreen Boots Alliance has two retail divisions, Retail Pharmacy USA and Retail Pharmacy International and a wholesale division., and is the largest retail pharmacy, health and daily living destination across the US and Europe. The Home Depot is a home improvement supplies retailer and while it principally trades within the US, it also has operations in Canada, Mexico and China. Target, which can trace its retail origins back to 1902 , is a discount retailer specialising in general merchandise and operates from over 1,800 stores throughout the US. As some of the leading players within the US retail sector of the economy, the five retailers might be expected to reflect innovative approaches in their contributions to sustainable development.

Retailers have employed a range of methods to report on their sustainable development commitments and achievements, but publication on corporate websites has become the most popular and the most accessible reporting mechanism [28]. With this in mind, the authors conducted an Internet search using the phrase 'sustainable development report' and the names of each of five selected US retailers. This search was conducted in January 2019, using Google as the search engine. The retailers' most recently posted sustainable development reports were chosen for study in order to present the retailers' current published thinking on 
Citation: Jones P, Comfort D (2019) Business Contributions to Sustainable Development: A Study of Leading US Retailers. Adv Environ Stud 3(1):132-140

their approach to sustainability. These reports are sizeable documents, the Walmart report runs to 232 pages and the corresponding figures for Kroger, Walgreen Boots Alliance, Target and The Home Depot are 142, 92, 84 and 94 pages respectively. The reports, whose sources are listed at the end of this paper, provided the empirical material for this paper, and unless specifically cited all the quotations were drawn from the retailers' sustainable development reports. In reviewing the selected retailers' sustainability reports the authors were guided by loose-grounded theory and took the decision to tease out the key themes and narratives by a close inspection of the sustainability reports on the selected companies' corporate web sites, rather than to employ content analysis. The authors argue that this approach was justified in an exploratory study in which the chosen material and themes were used for illustrative purposes, with the principal aim being to review the ways in which the retailers reported on their contributions to sustainable development, rather than to offer any comparative analysis of such contributions. The study was based on information that is in the public domain, and the authors took the considered view that they did not need to contact the selected retailers to obtain formal permission to cite any of this information.

\section{The Retailers' Sustainable Development Commitments and Achievements}

All five selected retailers reported on their commitment to sustainable development, often within the context of their wider strategic business commitments. Walmart [29], for example, 'aims to provide safe, affordable food and other products to people around the world. Doing so in a way that enhances economic opportunity, environmental and social sustainability and local communities, and creates value for our business and for society'. In a similar vein, Kroger [30] claimed that 'Our 2020 Sustainability Goals help us prioritize our investments and efforts to become a more sustainable and responsible company. These goals are intended to drive efficiency in our own operations and increase environmental and social responsibility in our supply chain'. Walgreen Boots Alliance [31] reported being 'proud to be a Corporate Social Responsibility leader, setting the pace on some of the most important issues of our day, from healthcare and combatting climate change, to valuing diversity and fostering inclusion'.

Such corporate commitments to sustainability were evidenced across a wide range of environmental, social and economic agendas. The environmental issues addressed included climate change and greenhouse gas emissions; water and energy conservation; waste management and recycling; sustainable sourcing; the protection and preservation of natural resources; minimising environmental impacts. In addressing climate change, for example, Target [32] reported 'recognising that we all have a role to play in combatting the impacts of climate change, we have developed science-based climate goals that should help us build a resilient business and contribute to a thriving environmen'. Further Target [32] claimed 'to combat the impacts of climate change and run our business more sustainably, we are aiming to reduce our GHG emissions and increase the energy efficiency of our operations' [32].
Walmart [29] claimed 'we want to be part of the solution by working hard to reduce emissions in our operations and supporting reductions across global value chains. Walmart believes business can play a role in addressing climate change by reducing GHG emissions, and our investments in renewable energy and efficiency underscore that belief. These actions are good for our business, good for our customers, and good for our environment'.

Both water and waste management were reported as a priority for all five retailers. The Home Depot [33], for example, reported 'we work with suppliers to ensure products reflect our conservation values and help customers use less water' and estimated that 'our products helped customers save 79 billion gallons of water last year alone'. Walmart [29] recognised that 'water scarcity has become a significant challenge in many communities where our customers, associates and suppliers live' and reported on its initiatives to measure and manage water use and to treat and recycle water within its own operations. Walgreen Boots Alliance [31] reported 'we are focused on improving waste reduction in our largest operation, our US retail stores' while Kroger [30] emphasised 'we're committed to becoming a zero waste company by 2020 through minimized waste diversion from landfill for better uses'.

Commitments to the conservation of natural resources featured in some of the retailers' sustainable development reports. The Home Depot [33], for example, outlined its commitment to 'sustainable forestry', under the strap line 'using the planet's resources wisely', and reported that since 1999 the company had been working to protect endangered forests and to ensure timber supplies for future generations. More generally, Walmart [29] recognised 'our environmental impact extends far beyond retail operations, up and down the value chains that deliver food, apparel, electronics and many other products to our customers' and reported 'working to help reduce environmental impacts from the farm to the factory to the consumer'.

In addressing social issues a number of common themes were identified within the retailers' sustainable development reports, including; responsible sourcing; food safety; working conditions at suppliers; diversity and equality of opportunity; training and development; employee health and safety within the workplace; work with local communities; and charitable donations. Walgreen Boots Alliance [31], for example, reported on its 'early career programs, career support and training' and on its work in tackling high levels of unemployment among young people in Chicago. The Home Depot [33] reported striving 'to build a learning-rich workplace where associates and leaders are prepared to succeed, motivated to serve our customers and given opportunities to grow'. More generally, Target [32] claimed 'our team members are what the Target brand is all about. As we look toward the future, we are continuing to invest in our nearly 350,000 team members and create good jobs that allow them to thrive'.

Kroger [30] claimed 'We put our customers and communities at the center of everything we do. Because we care, we continually improve the shopping experience and 
more, making our communities better places to live and work. Being a trusted partner in our communities is a top priority'. In reporting on its commitment to its customers, Kroger [30] suggested that by 'focusing on health and nutrition we encourage our customers to include more healthful and nutritious products, including organics, in their baskets to improve health'. Under the banner 'Strengthening Local Communities', Walmart [29] argued 'the local communities where our stores are located and where our customers and associates live are the cornerstones of our business'. More specifically here, Walmart [29] reported on its initiatives in 'relieving hunger', 'providing disaster relief', 'supporting communities' and 'supporting veterans and military families'. In focussing on disaster relief, for example, Walmart [29] reported on its work in supporting communities hit by hurricanes in Florida and Puerto Rica, by earthquakes in Mexico and by flooding in China.

Economic issues generally receive more limited explicit coverage but included employment creation; local economic development; supplier relationships; building shareholder value; and corporate governance. Under the banner 'We accelerate economic development', Target [32], for example, argued 'by investing in the places where we live and work, we create more sustainable communities for future generation'. Further Target [32], claimed 'now we want to go further, becoming intentional about how our businesses can accelerate economic development' and 'to bring Target to communities where our presence and investment can foster economic vitality'. Walmart [29] reported on its work in 'growing a local and inclusive supply base' and in training 'more than 1 million small- and medium-scale farmers'. In addressing corporate governance, The Home Depot [33], stressed its commitment to 'maximizing long term shareholder value' and outlined the work of its Audit Committee, which 'oversees the company's major financial exposures and compliance risks'.

The retailers illustrated their achievements in looking to meet their commitments in a number of ways within their sustainable development reports. Most commonly, achievements were illustrated with a brief narrative, which included, or were accompanied by, some simple descriptive statistics. Walmart [29], for example, provided highlight statistics to illustrate that $28 \%$ of its electricity was from Renewable sources, that by the end of $2017,78 \%$ of its global waste was being diverted from landfill and that 34 million acres had been committed to fertiliser optimization programmes. While extended time series data was generally conspicuous by its absence from the retailers' sustainable development reports, Walgreen provides some comparative data, including statistics, for carbon dioxide emissions, waste diversion from landfill and corporate giving, for 2016 and 2017. Some of the retailers' sustainable development reports included measures of their achievements against their commitments and goals. Target, for example, reported progress on 32 of its goals, for example, spanning, water stewardship, recycling, deforestation and renewable energy, in 2017 and outlined its future plans to advance its sustainability strategy. In a similar vein, Walmart provided measures of progress against its commitments up to 2018 across a range of agendas including, cre- ating economic opportunity for suppliers, fostering inclusion, renewable energy, eliminating waste and animal welfare.

Two general themes were identified in a number of the retailers' sustainable development reports, namely the importance attached to the role of innovation and technology and of the development of the circular economy in promoting and supporting the transition to a more sustainable future. Kroger [30], for example, reported on its innovative Food Recovery System' which 'converts food waste and dairy plant effluent into renewable energy through anaerobic digestion' and that the company was looking for opportunities to leverage this technology elsewhere'. Walmart stressed its role in promoting innovation amongst its suppliers and in its ordering processes, in accelerating innovation in the use of renewable energy resources, in testing innovations in the development of its e-commerce operations and in investing in innovation in eliminating criminal practices within its supply chains. Target [32] claimed 'innovation is an important part of our growth' and provided outline details the development of its 'retail accelerator capability', which looks to bring 'new technology, experiences, products and solutions to retail'.

A number of retailers emphasised their emerging commitment to the circular economy. Target (2018) [32], for example, reported 'our aspiration to develop a comprehensive circular strategy builds on extensive work to date to address the environmental impacts of our business, including our efforts to reduce waste, invest in renewable energy and pursue sustainable water management'. In a similar vein, Kroger [30] reported the company had 'taken meaningful strides to embrace the circular economy in our business' and here the 'key principles' included 'designing out waste and pollution, keeping products and materials in use, and regenerating natural systems'. Walmart [29] argued 'today we have a deeper understanding of the challenges and are engaging suppliers and customers in pursuit of the circular economy, in which products are made, consumed and recycled in a continuous loop'. Further, Walmart [29] claimed 'we hope to help create a more circular economy, moving away from a take-make-dispose approach to one where resources are preserved in production, and the materials and other component parts are ultimately recycled back into the economic stream'.

\section{Discussion}

The five selected retailers publicly reported on their sustainability commitments and achievements and as such this provided valuable insights into how businesses, within one sector of the economy, look to contribute to sustainable development. That said, a number of issues merit discussion. Firstly, while the retailers emphasised their commitment to sustainable development, the term sustainable development, was rarely explicitly, defined. Rather the retailers' approach to sustainable development was primarily built around business efficiency and was driven as much by business imperatives as by a fundamental concern for environmental and social sustainability. The accent being on efficiency gains across a wide range of economic, social and environmental issues rather than on maintaining the viability of natural ecosystems 
and reducing demands on finite natural resources. Certainly, the retailers consistently emphasised business continuity as much as the preservation and enhancement of natural and social capital.

Thus, while many of the environmental agendas addressed by the retailers were designed to reduce carbon dioxide emissions and to increase energy efficiency, for example, they also serve to reduce operating costs. In a similar vein, the retailers' commitments to their employees focusing for example, upon health and safety, empowering employees, career progression and staff development programmes, help to promote stability, security, loyalty and efficiency amongst the workforce. Here Banerjee's [34] beliefs that 'despite their emancipatory rhetoric, discourses of corporate citizenship, social responsibility and sustainability are defined by narrow business interests' and that they 'serve to curtail the interests of external stakeholders', clearly resonate.

Secondly, the importance of creating value was emphasised in the retailers' sustainable development reports. Value creation has traditionally been seen as one of the major objectives of businesses, though in posing the question 'for whom is value created', Haksever et al. [35] drew attention to whether companies must create value for its shareholders or more generally for all. In addressing value creation, a number of the leading retailers detailed benefits to both shareholders and stakeholders and such would seem to reflect the concept of shared value, defined by Porter and Kramer [36] as 'policies and practices that enhance the competitiveness of a company while simultaneously addressing the economic and social conditions in the communities in which it operates'. That said, Crane, et al. [37] identified a number of weaknesses and shortcomings in the creation of a shared value model. More specifically, Crane, et al. [37] argued that the model 'ignores the tensions between social and economic goals', that it is 'naïve about the challenges of business compliance' and that it is 'based on a shallow conception of the corporation's role in society'. In examining the first of these concerns, for example, Crane, et al. [37] suggested that 'many corporate decisions related to social and environmental problems, however creative the decision-maker may be, do not present themselves as potential win-wins, but rather manifest themselves in terms of dilemmas'. As such, Crane, et al. [37] suggested that such dilemmas are effectively 'continuous struggles between corporations and their stakeholders over limited resources and recognition'.

Thirdly, although the retailers addressed a range of environmental, social and economic agendas in their sustainability reports, many of their claims, were not evidenced. Thus, the claims 'we put our customers and communities at the center of everything we do' and we are 'working to help reduce environmental impacts from the farm to the factory to the consumer', cited earlier in the paper, are effectively little more than 'feel good' self-presentation statements. In a similar vein, the retailers' claim to be increasingly embracing the circular economy and to be looking to pursue a more circular business model can at best be seen as aspirational statements, with little specific evidence being presented to in their sustainable development reports, to

\section{substantiate such claims.}

More systematically, there is also an issue about the independent assurance of the data provided to illustrate achievements against these agendas. Some of the retailers commissioned independent assurance of the data in their sustainability reports, but this practice was not universal. Walgreen Boots Alliance [31], for example, commissioned Deloitte to produce an assurance report, which covered 13 'environmental indicators', including carbon dioxide emissions from a number of sources, energy use and waste disposal, as well as indicators for 'corporate giving' and the 'workplace'. By way of contrast, Kroger [30] claimed 'we align with several external initiatives to structure our sustainability strategy' and that these alignments provide 'third party credibility to our work', but none of their data on sustainability achievements was independently verified. Walmart [29] simply stated 'we did not seek external assurance for this report'. A failure to commission independent external assurance of the sustainability reporting process can be seen to undermine the validity and credibility of that process. That said, the five retailers are large, complex and dynamic organisations and capturing and storing comprehensive information and data throughout the supply chain in a variety of geographical locations and then providing access to allow external assurance is a challenging and a potentially costly venture.

Finally, there are broader issues around the underlying tensions between sustainability and economic growth. With an eye to the future, the retailers' sustainable development reports were couched within the idiom of continuing growth and business expansion. In some ways, this reflects the distribution sector's general position as epitomized by Sir Terry Leahy, the then Chief Executive Officer of largest UK retailer Tesco, in his 'Foresight' contribution at the start of The Global Coca Cola Retailing Research Council Forum [38] report. He argued that, at that time, his company was 'seeking to create a movement which shows that it is possible to consume, to be green and to grow'. Such an approach is rooted in the general belief that continuing economic growth will be accompanied by the more efficient use of resources. This trend, which is seen as either relative or absolute decoupling (relative decoupling refers to using fewer resources per unit of economic growth while absolute decoupling refers to a total reduction in the use of resources) underpins many conventional definitions of sustainable development and the vast majority of current corporate sustainable development strategies. However, Wiedmann, et al. [39] argued that 'achievements in decoupling in advanced economies are smaller than reported or even non-existent' and this, in turn, may be seen to ultimately undermine the concept of sustainable growth.

In looking to reconcile sustainable development and economic growth through the more efficient use of resources, a number of leading retailers emphasised the role of technological innovation and their move to adopt a more circular economy in their businesses. Many corporate approaches to sustainable development are rooted in 'the orthodox view' that 'achieving sustainability is a technical issue' requiring 'better knowledge, incentives and technology' 
Citation: Jones P, Comfort D (2019) Business Contributions to Sustainable Development: A Study of Leading US Retailers. Adv Environ Stud 3(1):132-140

[40]. Schor [41] suggested 'much of the literature on sustainable consumption has focused upon technological solutions' and claims that 'advocates of technological solutions argue that more intelligent design and technological innovation can dramatically reduce or even stop the depletion of ecological resources, as well as eliminate toxic chemicals and ecosystem disruption. Clark and Dickson [42] suggested that the need for sustainable development initiatives to mobilize appropriate science and technology has long been recognized' and technological innovation is widely seen to offer a means of promoting production efficiency. However, Alexander [43] argued that the view that technology can solve the world's most pressing environmental problems is flawed, and will in fact drive greater damage to the world, its ecosystems and us'.

Some of the leading retailers' enthusiasm for the circular economy can also be seen as a cause for concern. Not least, about how the concept might be captured by the retailers, to justify continuing economic growth, despite concerns about the overconsumption of natural resources and the damaging environmental effects of such growth. Valenzuela and Bohm [44], for example, suggested that 'given the all too obvious environmental crises associated with outof-bounds capitalism, the circular economy has been one of the main references for rebuilding a political economy of sustainable growth'. Valenzuela and Bohm [44] further argued the terms circular economy and sustainability were effectively being 'captured by politic-economic elites claiming that rapid economic growth can be achieved in a way that manages to remain responsible to environment and society'. In their conclusions, Valenzuela and Bohm [44] pessimistically suggest that the closer we get to the ideal of a fully circular economy, the more we are allowed to consume without taking an ethico-political stance'.

\section{Conclusions}

The five selected US retailers reported on their commitment to sustainability and they evidenced these commitments across a wide range of environmental, social and economic agendas. That said, the authors would argue that leading retailers' commitments to, and definitions of, sustainable development can be interpreted as being primarily driven by business imperatives. The accent being on making efficiency gains across a wide range of economic, social and environmental issues, rather than on maintaining the viability and integrity of natural ecosystems and on reducing demands on finite natural resources. At the same time, some critics [45] would suggest that corporate approaches to sustainable development and sustainability reporting amount to little more than so-called greenwash. Basically, a cynical ploy to attempt to assuage governments, consumers, and pressure group concerns about the environmental and social impacts of business activities. Equally critically, the authors suggested that the leading US retailers' commitments to sustainability are couched within existing business models centred on continuing growth, and that these commitments represent a weak approach to sustainability. As such, this echoes Roper's [8] belief that weak sustainability represents 'a compromise that essentially requires very little change from dominant econom- ic driven practices but effectively works to defuse opposition, increase legitimacy and allow business as usual'.

The findings of this exploratory study have some implications for the retail industry in the US and for more generally for retailers elsewhere in the world. Firstly, it is important to recognise that the retail industry in the US is effectively embarking on what may well be a long and challenging voyage towards sustainability. In its 'Retail Sustainability Management Report 2017', the US Retail Industry Leaders Association [46], for example, claimed that the 'environmental and social considerations were beginning to supplement traditional measures of completion including price, service and quality' in reports by 2012, but suggested that many retailers still have some way to go in developing 'the business case for sustainability'. As part of that process, US retailers may wish to consider commissioning comprehensive independent external assurance to enhance the reliability and the credibility of their reporting processes and to strengthen their commitment to the development of a circular economy approach to their business models. Both of these courses of action will have major financial implications for the retailers and the move to a more circular business model will demand major changes in consumer behaviour and consumption patterns. While the leading US retailers are publicly committed to sustainable development, such commitment seems likely to be constrained by business imperatives and at best, changes seem likely to be slow and measured.

In many other developed countries, large retailers who are also publicly committed to sustainable development face the same challenges in making genuine commitments to the transformation to a more sustainable future. In Europe, for example, where the European Commission is looking to work with the retail industry to develop best practices on sustainability in the retail sector [47] all the retailers initiatives are voluntary and carry little or no regulatory sanction. Within the developing world, retailers may face increasing pressure to demonstrate their commitment to sustainable development. That said, in many emerging markets, government, media and public scrutiny of the environmental, social and economic impact of retailers' practices and business models is currently limited, not least because of the current focus on economic growth and more specifically on the growth of consumer markets. Here the introduction of government policy or legislation on sustainable development within the retail sector seems unlikely in the foreseeable future.

More generally, the five selected US retailers' sustainable development reports offer a rich and accessible source of material for scholars wishing to explore ways in which businesses are looking to contribute to sustainable development. On the one hand, the reports provide a wealth of accessible information and detail on the environmental, social and economic contributions the leading retailers claim to be making to sustainable development and on the ways in which these retailers publicly perceive sustainable development challenges and frame their responses to them. On the other hand, the reports also provide important opportunities for scholars to review and reflect on companies' sustainable development 
commitments and achievements and to engage with them in order to tease out the complexities of business engagement with sustainable development. While this short paper has focussed on the retail industry, companies in many other sectors of the economy also publicly report on their sustainable development commitments and achievements, and they too offer a rich and accessible source for environmental enquiry.

\section{References}

1. United Nations (2018) About the sustainable development goals.

2. United Nations Global Compact (2018) Global goals for people and planet.

3. Fahy F, Rau H (2013) Methods of sustainability research in the social sciences.

4. Du Pisani JA (2006) Sustainable development-historical roots of the concept. Environmental Sciences 3: 83-96.

5. Stewart Barr (2008) Environment and society: Sustainability, policy and the citizen. Ashgate, Aldershot.

6. World Commission on Environment and Development (1987) Our Common Future.

7. Hudson R (2005) Towards sustainable economic practices, flows and spaces: Or is the necessary impossible and the impossible necessary? Sustainable Development 13: 239-252.

8. Roper J (2012) Environmental risk, sustainability discourses and public relations. Public Relations Inquiry 1: 69-87.

9. KPMG (2012) Corporate Sustainability.

10. Dyllick T, Hockerts K (2002) Beyond the business case for corporate sustainability. Business Strategy and the Environment 11: 130-141.

11. van Marrewick M, Were M (2002) Multiple levels of corporate sustainability.

12. Amini M, Bienstock CC (2014) Corporate sustainability: An integrative definition and framework to evaluate corporate practice and guide academic research. Journal of Cleaner Production 76: 12-19.

13. Stoughton AM, Ludema JD (2012) The driving force of sustainability. Journal of Organizational Change Management 25: 501-517.

14. Lock I, Steele P (2016) The credibility of CSR reports in Europe. Evidence from a quantitative content analysis in 11 countries. Journal of Cleaner Production 122: 186-200.

15. Swarnapali N (2017) Corporate sustainability: A Literature review. Journal of Accounting Researchers and Educators 1: 1-16.

16. Baumgartner RJ, Ebner D (2010) Corporate sustainability strategies: Sustainability profiles and maturity levels. Sustainable Development 18: 76-89.

17. Bonilla-Priego MJ, Font X, Pacheco-Olivares M del R (2014) Corporate sustainability reporting index and baseline data for the cruise industry. Tourism Management 44: 149-160.

18. de Grosbois D (2016) Corporate social responsibility reporting in the cruise tourism industry: A performance evaluation using a new institutional theory based model. Journal of Sustainable Tourism 24: 245-269.

19. Jones P Comfort D, Hillier D (2017) European food and drink wholesalers and sustainability. European Journal of Sustainability 1: 1-12.
20. Wagner M (2005) How to reconcile environmental and economic performance to improve corporate sustainability: corporate environmental strategies in the European paper industry. Journal of Environmental Management 76: 105-118.

21. Jones P, Hillier D, Comfort D (2014) Sustainability in the global hotel industry. International Journal of Contemporary Hospitality Management 26: 5-17.

22. Garvare R, Johansson P (2010) Management for sustainability-a stakeholder theory. Total Quality Management 21: 737-744.

23. Amsler SS (2009) Embracing the politics of ambiguity: Towards a normative theory of sustainabilit. Capitalism, Nature and Socialism 20: 111-125.

24. Castro C (2004) Sustainable development: Mainstream and critical perspectives. Organisation and Environment 17: 195-225.

25. Deloitte (2019) Global Powers of Retailing 2019.

26. Wiese A, Zielke S, Toporowski (2015) W Sustainability in retailingresearch streams and emerging trends. International Journal of Retail and Distribution Management 43.

27. Durieu X (2003) How Europe's retail sector helps to promote sustainable production. Industry and Environment 26: 7-9.

28. Morhardt JE (2009) Corporate social responsibility and sustainability reporting on the internet. Business Strategy and the Environment 19: 436-452.

29. Walmart (2018) 2018 Global Responsibility Report.

30. Kroger (2018) Setting the table for a sustainable future: The kroger family of companies 2018 sustainability report.

31. Walgreen Boots Alliance (2018) Corporate social responsibility report 2017.

32. Target (2018) Future at heart: 2018 target corporate responsibility report.

33. The Home Depot (2019) 2018 Responsibility report.

34. Banerjee SB (2008) Corporate social responsibility: The good, the bad and the ugly. Critical Sociology 34: 51-79.

35. Haksever C, Chaganti R, Cook RG (2004) A model of value creation: Strategic view. Journal of Business Ethics 49: 291-305.

36. Porter ME, Kramer MR (2011) Strategy and society: The link between competitive advantage and corporate social responsibility. Harvard Business Review 87: 78-92.

37. Crane A, Palazzo G, Spence LJ, et al. (2014) Contesting the value of creating shared value. California Management Review 56: 130-154.

38. The Global Coca Cola Retailing Research Council Forum (2009) Sustainability in retailing.

39. Wiedmann TO, Manfred S, Lenzen M, et al. (2015) The material footprint of nations. Proceedings of the National Academy of Sciences 112: 6271-6276.

40. Mansfield B (2009) Sustainability' in 'A Companion to Environmental Geography. In: Castree N, Demeriff D, Liverman D, et al., Wiley, London, 37-49.

41. Schor JB (2005) Prices and quantities: Unsustainable consumption and the global economy. Ecological Economics 55: 309-320.

42. Clark WC, Dickson NM (2003) Sustainability science: The emerging research program. Proceedings of the National Academy of Sciences in the United States of America 14: 80598061. 
Citation: Jones P, Comfort D (2019) Business Contributions to Sustainable Development: A Study of Leading US Retailers. Adv Environ Stud 3(1):132-140

43. Alexander S (2015) The green tech future is a flawed vision of sustainability.

44. Valenzuela F, Bohm S (2017) Against wasted politics: A Critique of the circular economy. Ephemera: Theory and Politics in Organization 17: 23-60.

45. Hamilton C (2009) Consumerism, self-creation and prospects for a new ecological consciousness. Journal of Cleaner Production 18: $571-575$.

46. Retail Leaders Industry Association (2017) Retail sustainability management report 2017.

47. European Commission (2016) Retail forum.

DOI: $10.36959 / 742 / 212$

Copyright: (C) 2019 Jones $\mathrm{P}$, et al. This is an open-access article distributed under the terms of the Creative Commons Attribution License, which permits unrestricted use, distribution, and reproduction in any medium, provided the original author and source are credited. 